\title{
The Current Barriers and Management Strategy to Increase the Use of Long Acting Reversible Contraception Methods
}

\author{
Amany Hamed Gad ${ }^{1}$, Manar Fathy Heeba ${ }^{2}$, Mervat Mostafa Abd El Monem ${ }^{3}$, \& Hanan Morsy Salim ${ }^{4}$ \\ 1. Assistant Professor of Obstetrics \& Gynecological Nursing - Faculty of Nursing - Zagazig University, Eygpt \\ 2. Assistant Professor of Maternity,Obstetrics \& Gynecological Nursing-Faculty of Nursing-Port-Said University, Egypt \\ ${ }^{3 .}$ Lecturer of Obstetrics \& Gynecological Nursing - Faculty of Nursing - Zagazig University, Egypt \\ 4. Lecturer of Obstetrics \& Gynecological Nursing - Faculty of Nursing - Zagazig University, Egypt
}

\begin{abstract}
:
Long acting reversible contraception methods (LARCs) are ideal pregnancy prevention options for many women compared with shorter-term methods. Aim: to assess the current barriers and management strategy to increase the use of LARCs. Subjects and methods: A cross-sectional design was used. Setting: Conducted at 5 family planning units at Sharkia governorate, Egypt. Subjects: A representative sample of 225 woman who were attended the selected family planning units between the period from January to December 2020. Tools: Two tools were used to collect the study data; socio-demographic characteristics questionnaire and barriers of LARCs questionnaire.

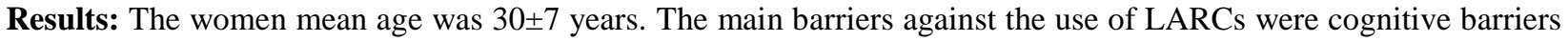
followed by requiring woman to return for check-ups and socio cultural barriers $(50.7 \%, 15.6 \%, 14.6 \%)$ respectively. Conclusion: The utilization of short acting contraceptive methods is higher than long acting methods and cognitive barriers were the main barriers for LARC utilization. Recommendations: Increase women's awareness about the importance of using family planning methods especially LARCs.
\end{abstract}

\section{Keywords: Barriers, Long acting reversible methods \& Management strategy.}

\section{Introduction}

Family planning is cost-effective intervention to improve maternal and child health through reducing high risk pregnancies and lowering unintended pregnancies (Gayatri, 2020). Methods of long-acting reversible contraceptives, as contraceptive implants and intrauterine devices are reliable and safe contraceptive alternatives with elevated continuation rates and low failure rates, they don't need daily usage or coital adherence and away from the side effects and health hazards associated with estrogencontaining contraceptives (Zenebe et al., 2017).

The most of maternal and newborn mortality can be avoided by implementing validated measures to ensure that every pregnancy is desired and that every newborn is healthy as well as removing obstacles to contraception use and improving the need for family planning could prevent 54 million unwanted births, over 79,000 maternal mortality and over one million child deaths yearly (Kumari, 2016).

Long-acting contraceptive methods (LARCs) including implant, progesterone only injectable, and intrauterine contraceptive device (IUCD) are more efficient and suitable with benefit of being long lasting. This has elevated levels of compliance than hormonal approaches and therefore inexpensiveeffective. LARCs are a great way to avoid becoming pregnant compared to short term contraception (Bolarinwa \& Olagunju, 2019). LARCs virtually eradicate contraceptive failure as it is not userdependent; however, its uptake has been low (Azmoude et al., 2017).

Long-acting reversible contraceptive is a form of birth control that gives 99 percent successful for a prolonged period of time without involving consumer intervention. They avoid unplanned pregnancy for at least 3 years with implants and 12 years with copper T- IUCD, and when they are removed, fertility returns quickly (Bhandari et al., 2019).

The causes for stopping LARCs were classified to six separate categories: failure of the method, want pregnant, other reasons related to fertility, side effects/health complications, desired efficient contraception and additional method-related explanations (Farrag et al., 2020). Around the world, contraceptive failure accounts for $48 \%$ of unwanted births, which is mostly attributed to inappropriate usage, inadequate adherence, and/or technology failure. (Zenebe et al., 2017).

In Egypt, while physical and administrative factors play insignificant role in shaping patterns of FP practice, certain socio-demographic, cultural, and reproductive factors act as barriers that limit FP use, increase discontinuation rates and increase the unmet need of FP. Identifying these barriers helps guide policy and decision makers determine where efforts should be directed to promote efficiency of the FP services (Farrag et al., 2020). 
There is a challenge for Egypt to achieve its millennium development goals (MDGs); reducing under-five child mortality by two thirds per 1000 live births (Goal 4), and enhance maternal health by reducing the ratio of maternal mortality by three quarters per 100,000 live births (Goal 5). Therefore, detecting the accurate prevalence and barriers that prevent the utilization of LARCs will have a huge input to design a strategy for women to encourage them for increasing usage of LARCs (Farrag et al., 2020).

\section{Significance of the study}

Egypt is the third populous country in Africa after Ethiopia which is ranked $14^{\text {th }}$ with a population that exceeds 100 million (EDHS, 2020). Egypt is currently witnessing a decline in LARCs as well as a high rate of unintended pregnancy. To the best of researcher's awareness, there were few studies conducted in Sharkia governorate, Egypt to assess current barriers and management strategy to increase the use of long acting reversible contraception methods. Hence, we are conducting this study to assess the current barriers and management strategy to increase the use of LARCs.

\section{Aim of the study}

The aim of the study was to assess the current barriers and management strategy to increase the use of long acting reversible contraception methods (LARCs).

\section{Research questions:}

1- What is the rate of utilization of different types of long acting reversible contraception methods among studied women?

2- What are the current barriers against use of long acting reversible contraception methods?

\section{Subjects and Methods:}

Design of the Study: A cross-sectional design was used in this study.

\section{Study setting:}

The current research was carried out at 5 family planning centers and units at Sharkia governorate, Egypt. Where there was 31 family planning center and unit in Kafr Sakr city. Five family planning centers and units were chosen as representative, four rural health units and one urban family planning center. These units were been chosen because their flow rate was high.

\section{Sample type and size:}

According to assuming the percent of long acting reversible contraception methods was 30.1\% according to El-Zanaty \& Way, (2014). The total women using contraception methods in Qafr Sakr were 84404 during the period from January to
December 2020 obtained from the ministry of health statistical records calculated.

Study subjects included a convenience sample of 225 mothers who attended the selected five family planning center and units, which was a representative sample of the whole number of women who attended Kafr- Sakr family planning units and centers during the year 2020 (84404 women).

Sample equation $=Z^{2} \times P x q / d^{2}$

- $\mathrm{Z}=$ Confidence interval $=1.96$.

- Confidence limit of $95 \%$.

- $\mathrm{P}=$ the least prevalence of utilization in Egypt = $30.1 \%$.

- $\mathrm{q}=100-\mathrm{p}=70 \%$.

- $\mathrm{d}=$ Maximum accepted error $=$ Level of significance $10 \%$.

- Power of test $80 \%$.

Inclusion criteria:

Women of reproductive age (18-45 years) who were registered on the family statistical register at the selected health units.

\section{Exclusion Criteria:}

Women who were unable or refusing to participate in the study.

Tools of data collection: was done through the use of the following tool:

Tool I: Socio-demographic characteristics Questionnaire: was developed by the researcher and consists personal data as age, educational level, occupation, residence, income and data about family planning utilization.

Tool II: Barriers of LARCs questionnaire; was adopted from (Eltomy et al., 2013): Cognitive barriers which contain 6 questions:

Can woman return fertility after removal of long acting reversible contraceptives?, Hear or see any advertisement about LARC in last 6 months, Participate in an educational session about LARC during last 6 months, Heard about long acting and permanent family planning methods, Think that it is good for woman to use LARC and Does woman know how LARCs can prevent pregnancy?

Socio-cultural barriers which contain 8 questions: Have bad belief about LARC e.g. loop can penetrate the heart, implants might lead to permanent sterility, injection can cause infertility, implants could move around freely in the body once inserted and could be lost at the day of removal, Does long acting contraceptive affect women's' sexual life, and breastfeeding?, Can long acting reversible contraceptives cause irregular bleeding and cancer?, Child-bearing is more comfortable at a younger age, Nontraditional methods of family planning can harm the woman health, Reluctance to discuss sexual behaviors and problems with male physicians, Specific family composition of two or one girl and 
ideal number of children and Presence of male physician prevents women from being investigated.

Method failure barriers: contain 5 questions:

Desire to have the most effective method, Have failed in using LARC and causes of this failure, Became pregnant while using the method, Method used induced serious side effects such as severe pain in chest or abdomen, severe headache, severe depression, severe bleeding and Side-effects as pain, bleeding disturbances such as spotting or amenorrhea, infection, discomfort with regular checking of thread and doubts about method reliability were the common concerns.

Demographic and reproductive: Contain 5 questions:

Long intervals between intercourses, Desire to have children (number of living children) because of low parity, Used only for older women who don't want children/difficulty becoming pregnant (age), Someone bans you from using FP, e.g. husband, mother in-law, self, husband disapproval and Physical access engaged in activities throughout the day distance to clinic is long.

Administrative barriers: Contain 7 questions:

Poor quality of service, long waiting times or limited supply of methods, Shortage of stock, Previous bad experience with the facility service, Lack of trained staff, Negative provider's attitude, age restrictions to the use of some contraceptive methods, physicians would discourage contraceptive progesterone only injections and implants in a woman who has only one live birth, Come back at a later date while they were menstruating and Lack of privacy during examinations.

Medical barriers: contain 2 questions:

Requiring women to return more often than for check-ups and requiring spouse's consent as a prerequisite for prescribing contraception.

The scoring system for sociocultural, method failure, demographic and reproductive, administrative and medical barriers; yes, scored 1: the greater the score, the more obstacles there are. No scored 0 . While in cognitive barriers; No scored 1, do not know scored 1 , Yes scored 0 and represents no barrier. Presence of barrier $>60$ and no barrier $<60$.

\section{Validity and reliability:}

Face validity was reviewed by 4 professors of obstetrics nursing who reviewed the instruments for clarity, relevance comprehensive, understanding, applicability, and easiness for administration.

A pilot study was conducted on $10 \%$ of the mothers (23 women) to evaluate the content of the tool, their clarity as well as to estimate the time needed for filling the sheets with the collected data.
Field work:

The study was carried out in three phases (interviewing/assessment phase, implementation phase, and evaluation phase). The data were collected from five family planning units affiliated to the Ministry of Health in Kafr Sakr city, Sharkia governorate, Egypt. The data collection took one year: from January to December 2020. The researchers went to pre mentioned settings 3 days per week.

\section{I-Interviewing Phase:}

The researchers interviewed the women individually after obtaining their verbal agreement. Women who have fulfilled the inclusion criteria were included in the study. Women were divided into groups to facilitate collection of data; each group included ten women. Each woman was asked to fill the interviewing questionnaire and the researchers read out the tools to illiterate women. This phase took about 15-20 min. The sessions were conducted in the waiting areas of the previously mentioned settings.

II- Implementation phase:

At the beginning of the session the aim of the study was explained briefly to the woman and obtained their verbal agreement in order to establish good rapport. Each session took about 30-45 min. Audio visual aids and pictures were used. The researchers provide information about management strategy for the users and non-users and focus on information that will be critical to the women in making a choice and using the method consistently and correctly, provided needed information about the advantages, disadvantages, side effects and benefits of using LARCs. They should assess the amount of time available to cover critical information and tailor the counseling session to meet women's needs. It is important that the researchers be sensitive to women's cultural differences and religious beliefs. Ideally, researchers will establish an open dialogue with women so that they feel comfortable asking questions and returning for services in the future.

\section{III- Evaluation phase:}

Finally, the researchers provide a guidebook in Arabic language to each woman that describes each method's mechanism of action, relative efficacy, duration of use, adverse events, expected bleeding patterns and effects on fertility after discontinuation. In addition, procedures required for initiation/insertion and removal and steps to be taken if problems arise should be described. This took about $15-20 \mathrm{~min}$.

\section{Ethical Considerations:}

An official letter from the faculty of nursing was sent to the responsible authorities of the study setting to obtain their data collection permission. Written 
permission was taken from ethics committee of faculty of nursing $(64,22 / 7 / 2019)$.

Statistical design:

Data was analyzed using SPSS (Statistical Package for Social Sciences) version 15. Qualitative data was represented as number and percent. Comparison between groups was done by chi-Square test. Quantitative data was represented as mean $\pm \mathrm{SD}$, ANOVA test, correlation coefficient and paired t test were used if needed. $\mathrm{P}<0.05$ was considered to be statistically significant.

\section{Results}

Table (1): Socio Demographic Characteristics of Studied Women $(n=225)$

\begin{tabular}{|l|c|c|}
\hline Variables & no (225) & Percent (100\%) \\
\hline Age/ year & & 20.9 \\
\hline $20-<21$ & 47 & 23.1 \\
\hline $21-<29$ & 52 & 36.4 \\
\hline $29-<39$ & 82 & 19.6 \\
$39-40$ & 44 & \\
Mean \pm SD & $30 \pm 7$ & \\
Minimum-maximum & $20-40$ & 17.5 \\
\hline Education & & 8.4 \\
\hline Illiterate & 39 & 60.4 \\
\hline Primary & 19 & 13.8 \\
\hline Secondary & 136 & \\
\hline University & 31 & 14.7 \\
\hline Occupation & & 85.3 \\
\hline Employee & 33 & 20.0 \\
\hline House wives & 192 & 80.0 \\
\hline Residence & & \\
\hline Urban & 45 & 22.7 \\
\hline Rural & 180 & 58.2 \\
\hline Income & & 19.1 \\
\hline Sufficient & 51 & \\
\hline Just meet life expenses & 131 & \\
\hline Insufficient & 43 & \\
\hline
\end{tabular}

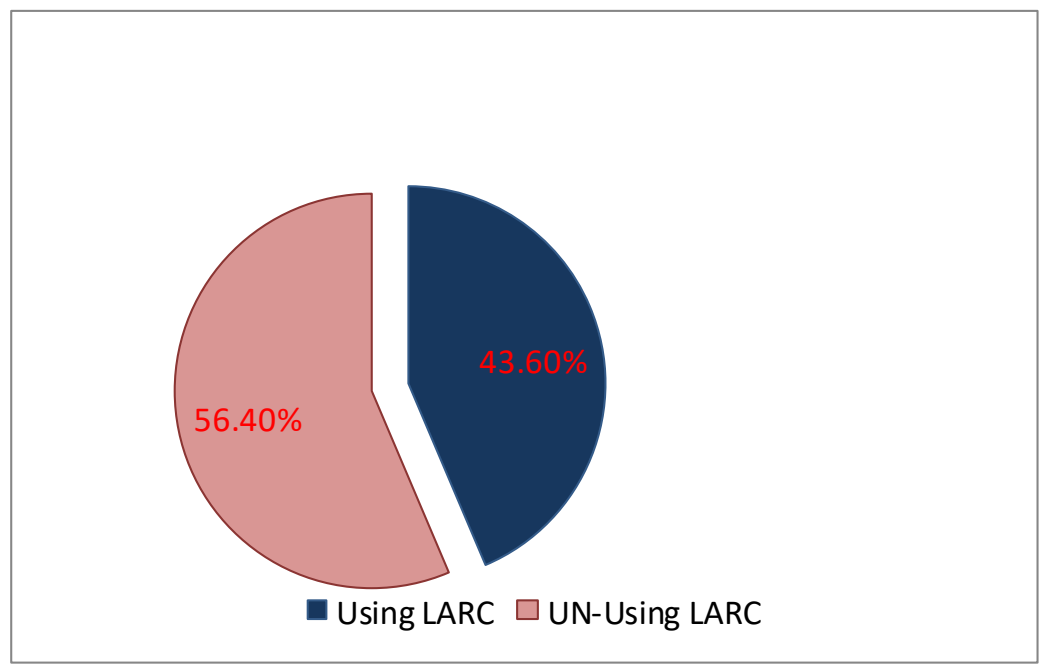

Figure (1): Percent of Using LARC among Studied Women 


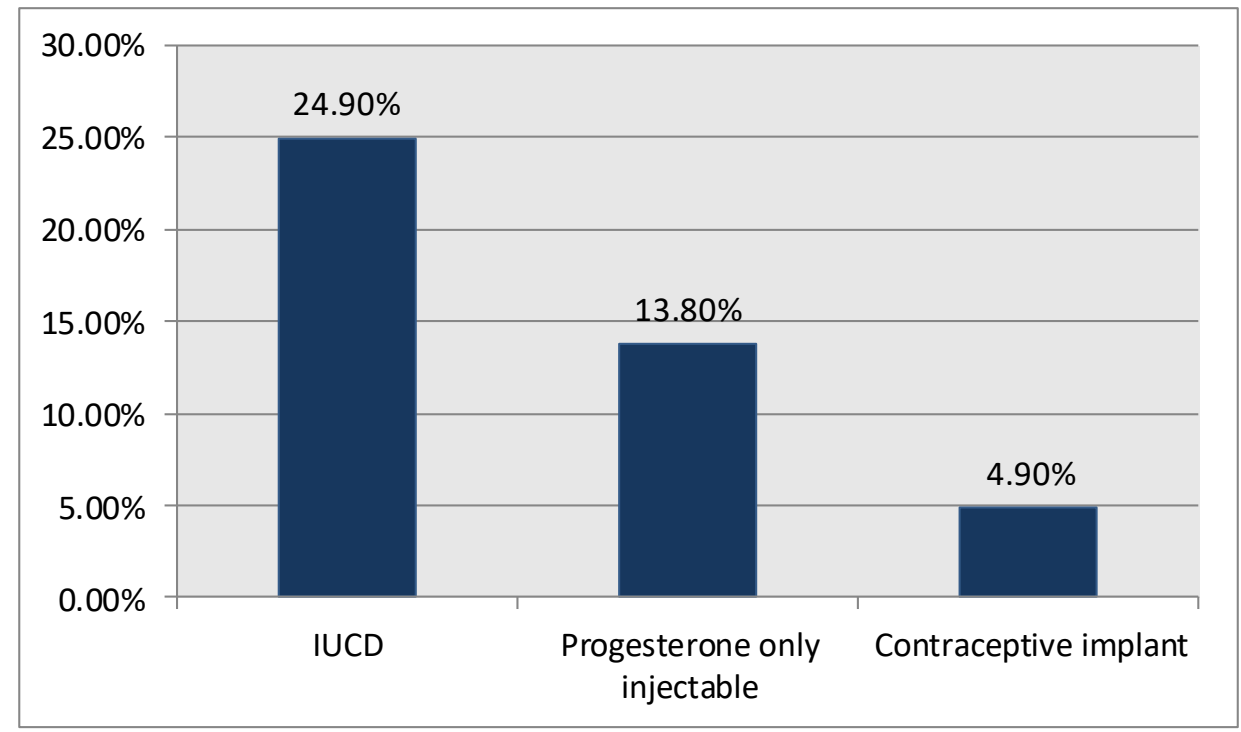

Figure (2): Types and Utilization of Long Acting Reversible Contraception

Table (2): Cognitive, Demographic and Reproductive Barriers of Long Acting Reversible Contraceptive Methods among Studied Women $(n=225)$

\begin{tabular}{|c|c|c|c|c|c|c|}
\hline \multirow{3}{*}{ Barriers } & \multicolumn{4}{|c|}{ Studied } & \multirow{2}{*}{\multicolumn{2}{|c|}{$\begin{array}{l}\text { Women } \\
\text { Do not } \\
\text { know }\end{array}$}} \\
\hline & \multicolumn{2}{|c|}{ Yes } & \multicolumn{2}{|c|}{ No } & & \\
\hline & $\mathbf{N}$ & $\%$ & $\mathbf{N}$. & $\%$ & N. & $\%$ \\
\hline \multicolumn{7}{|l|}{ 1. Cognitive Barriers $(n=225)$} \\
\hline $\begin{array}{l}\text { Can woman return fertility after removal of long acting } \\
\text { reversible contraceptives }\end{array}$ & 187 & 83.1 & 14 & 6.2 & 24 & 10.7 \\
\hline $\begin{array}{l}\text { Hear or see any advertisement about LARC in last } \\
6 \text { months }\end{array}$ & 4 & 1.8 & 221 & 98.2 & 0 & 0.0 \\
\hline $\begin{array}{l}\text { Engage in the last } 6 \text { months of a LARC education } \\
\text { session }\end{array}$ & 5 & 2.2 & 220 & 97.8 & 0 & 0.0 \\
\hline $\begin{array}{l}\text { Heard about long acting and permanent family planning } \\
\text { methods }\end{array}$ & 220 & 97.8 & 5 & 2.2 & 0 & 0.0 \\
\hline Think that it is good for woman to use LARC & 186 & 82.7 & 36 & 16.0 & 3 & 1.3 \\
\hline $\begin{array}{l}\text { Does woman know how long the long acting } \\
\text { contraceptive methods } \\
\text { prevent pregnancy }\end{array}$ & 141 & 62.7 & 19 & 8.4 & 65 & 28.9 \\
\hline \multicolumn{7}{|l|}{ 2. Demographic and Reproductive Barriers $(n=225)$} \\
\hline Long intervals between intercourse & 32 & 14.2 & 193 & 85.8 & 0 & 0.0 \\
\hline $\begin{array}{l}\text { Desire to have children (number of living children ) } \\
\text { because of low parity }\end{array}$ & 72 & 32.0 & 153 & 68.0 & 0 & 0.0 \\
\hline $\begin{array}{l}\text { Only used for elderly women who do not want children } \\
\text { to become pregnant }\end{array}$ & 80 & 35.6 & 145 & 64.4 & 0 & 0.0 \\
\hline $\begin{array}{l}\text { Someone prevents you from using family planning, as } \\
\text { husband, mother in law, self-disapproval, husband } \\
\text { rejection. }\end{array}$ & 16 & 7.1 & 209 & 92.9 & 0 & 0.0 \\
\hline $\begin{array}{l}\text { Accessibility to events is a long way from the clinic } \\
\text { during the day. }\end{array}$ & 42 & 18.7 & 183 & 81.3 & 0 & 0.0 \\
\hline
\end{tabular}


Table (3): Socio Cultural Barriers of Long Acting Reversible Contraceptive Methods among Studied Women $(\mathbf{n}=\mathbf{2 2 5})$

\begin{tabular}{|l|c|c|c|c|c|c|}
\hline \multicolumn{2}{|c|}{ Socio Cultural Barriers } & \multicolumn{2}{c|}{ Yes } & \multicolumn{2}{c|}{ No } & \multicolumn{2}{c|}{$\begin{array}{c}\text { Do not } \\
\text { know }\end{array}$} \\
\cline { 2 - 7 } & N. & \% & N. & \% & N. & \% \\
\hline $\begin{array}{l}\text { Getting negative experience of LARC as a loop may } \\
\text { perforate the heart. }\end{array}$ & 127 & 56.4 & 73 & 32.4 & 25 & 11.2 \\
\hline $\begin{array}{l}\text { Have bad belief about LARC e.g. when introduce, } \\
\text { implants can travel easily in the body. }\end{array}$ & 47 & 20.9 & 73 & 32.4 & 105 & 46.7 \\
\hline $\begin{array}{l}\text { Have bad belief about LARC e.g. Injection can cause } \\
\text { infertility }\end{array}$ & 97 & 43.1 & 85 & 37.8 & 43 & 19.1 \\
\hline $\begin{array}{l}\text { Have bad belief about LARC e.g. implants could move } \\
\text { around freely in the body once inserted and could be } \\
\text { lost at the day of removal. }\end{array}$ & 27 & 12.0 & 86 & 38.2 & 112 & 49.8 \\
\hline $\begin{array}{l}\text { Does long acting contraceptive affect women's sexual } \\
\text { life, and breastfeeding }\end{array}$ & 38 & 16.9 & 137 & 60.9 & 50 & 22.2 \\
\hline $\begin{array}{l}\text { Can long acting reversible contraceptives cause } \\
\text { irregular bleeding. }\end{array}$ & 123 & 54.6 & 69 & 30.7 & 33 & 14.7 \\
\hline Pregnancy is safe in younger age con danger health of the & 71 & 31.6 & 145 & 64.4 & 9 & 4.0 \\
\hline $\begin{array}{l}\text { Nontraditional contraceptives can } \\
\text { woman. }\end{array}$ & 146 & 64.9 & 79 & 35.1 & 0 & 0.0 \\
\hline $\begin{array}{l}\text { Reluctance to discuss sexual behaviors and problems } \\
\text { with male physicians }\end{array}$ & 45.3 & 123 & 54.7 & 0 & 0.0 \\
\hline $\begin{array}{l}\text { Ideal number of children and specific family } \\
\text { composition. }\end{array}$ & 114 & 50.7 & 111 & 49.3 & 0 & 0.0 \\
\hline $\begin{array}{l}\text { Presence of male physician prevent women from being } \\
\text { investigated }\end{array}$ & 77 & 34.2 & 148 & 65.8 & 0 & 0.0 \\
\hline
\end{tabular}

Table (4): Administrative, Method Failure and medical barriers of Long Acting Reversible Contraceptive Methods among Studied Women $(n=225)$

\begin{tabular}{|c|c|c|c|c|}
\hline \multirow{2}{*}{ Barriers } & \multicolumn{2}{|c|}{ Yes } & \multicolumn{2}{|c|}{ No } \\
\hline & N. & $\%$ & N. & $\%$ \\
\hline \multicolumn{5}{|l|}{ Administrative Barriers $(n=225)$} \\
\hline Poor quality of service, long waiting times or limited supply of methods & 35 & 15.6 & 190 & 84.4 \\
\hline Shortage of stock & 9 & 4.0 & 216 & 96.0 \\
\hline Previous bad experience with the facility service & 4 & 1.8 & 221 & 98.2 \\
\hline Lack of trained staff & 4 & 1.8 & 221 & 98.2 \\
\hline Negative provider's attitude & 6 & 2.7 & 219 & 97.3 \\
\hline Come back at a later date while they were menstruating & 78 & 34.7 & 147 & 65.3 \\
\hline Lack of privacy during examinations & 4 & 1.8 & 221 & 98.2 \\
\hline \multicolumn{5}{|l|}{ Method Failure Barriers $(\mathrm{n}=\mathbf{2 2 5})$} \\
\hline Want the more efficient contraceptive. & 44 & 19.6 & 181 & 80.4 \\
\hline $\begin{array}{l}\text { Failure use of LARC (because of: Pregnancy, serious side effects \& side } \\
\text { effects) }\end{array}$ & 43 & 19.1 & 182 & 80.9 \\
\hline Became pregnant while using the method & 5 & 2.2 & 220 & 97.8 \\
\hline $\begin{array}{l}\text { Extreme health problems like abdominal or chest pain ,headache, } \\
\text { depression, and serious bleeding }\end{array}$ & 16 & 7.1 & 209 & 92.9 \\
\hline Tolerable side-effects & 98 & 43.6 & 127 & 56.4 \\
\hline \multicolumn{5}{|l|}{ Medical Barriers $(\mathrm{n}=\mathbf{2 2 5})$} \\
\hline Women need to comeback a lot for check-ups & 35 & 15.6 & 190 & 84.4 \\
\hline $\begin{array}{l}\text { Requiring spouse's consent as a prerequisite for prescribing } \\
\text { contraception }\end{array}$ & 3 & 1.3 & 222 & 98.7 \\
\hline
\end{tabular}


Table (5): Relation between Cognitive, Socio Cultural, Method Failure, Demographic \& Reproductive, Administrative and Medical Barriers and Using LARC among Studied Women $(\mathrm{n}=$ 225).

\begin{tabular}{|c|c|c|c|c|c|c|}
\hline \multirow[b]{2}{*}{ Barriers } & \multirow[b]{2}{*}{ Variables } & \multicolumn{2}{|c|}{ LARC } & \multirow[b]{2}{*}{$\begin{array}{l}\text { Total } \\
(\mathbf{2 2 5})\end{array}$} & \multirow[b]{2}{*}{$\chi^{2}$} & \multirow[b]{2}{*}{$\mathbf{p}$} \\
\hline & & $\begin{array}{c}\begin{array}{c}\text { Users } \\
(n=98)\end{array} \\
\text { No }(\%)\end{array}$ & 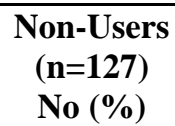 & & & \\
\hline \multirow[t]{2}{*}{ Cognitive } & high barriers & $34(29.8)$ & $80(70.2)$ & 114 & 17 & 0.0001 \\
\hline & low barriers & $64(57.7)$ & $47(42.3)$ & 111 & & (S) \\
\hline Socio cultural & $\begin{array}{l}\text { high } \\
\text { low }\end{array}$ & $\begin{array}{l}13(39.4) \\
84(44.0)\end{array}$ & $\begin{array}{c}20(60.6) \\
107(56.0)\end{array}$ & $\begin{array}{c}33 \\
191\end{array}$ & $\begin{array}{c}0.2 \\
4\end{array}$ & 0.62 \\
\hline \multirow{2}{*}{ Method failure } & high & $1(12.5)$ & $7(87.5)$ & 8 & $\mathrm{f}$ & 0.14 \\
\hline & low & $97(44.7)$ & $120(55.3)$ & 217 & & \\
\hline \multirow{2}{*}{$\begin{array}{l}\text { Demographic } \\
\text { reproductive }\end{array}$} & high & 0 & $3(100)$ & 3 & $\mathrm{f}$ & 0.26 \\
\hline & low & $98(44.0)$ & $124(56.0)$ & 222 & & \\
\hline \multirow{2}{*}{ Administrative } & high & 0 & $1(100)$ & 1 & $\mathrm{f}$ & 0.99 \\
\hline & low & $98(43.8)$ & $126(56.2)$ & 224 & & \\
\hline \multirow{2}{*}{$\begin{array}{l}\text { Requiring women to } \\
\text { return for check-ups }\end{array}$} & Yes & $31(88.6)$ & $4(11.4)$ & 35 & 34 & 0.0001 \\
\hline & No & $67(35.3)$ & $123(64.7)$ & 190 & & (S) \\
\hline \multirow{2}{*}{$\begin{array}{c}\text { Requiring spouse's } \\
\text { consent }\end{array}$} & Yes & 0 & $3(100)$ & 3 & $\mathrm{f}$ & 0.26 \\
\hline & No & $98(44.0)$ & $124(56.0)$ & 222 & & \\
\hline
\end{tabular}

Table (1): Describes socio demographic characteristics of studied women (225). It was found that $56.0 \%$ of the studied women were in the age group $29-40$ years, followed by $23.1 \%$ in the age group of $21-<29$, with mean \pm SD of $30 \pm 7$ years. Regarding educational level, $60.4 \%$ of women had secondary education. Concerning occupational status, it was found that $85.3 \%$ of women were house wives and $80.0 \%$ of them were living in rural areas. The same table also reported that $58.2 \%$ of their income was just meet life expenses.

Figure (1): Shows percent of using LARC among studied women. It revealed that less than half $(43.6 \%)$ of studied women were currently using LARC.

Figure (2): Shows types of using LARC among studied women. It revealed that intrauterine contraceptive device was commonly used (24.90\%).

Table (2): Measures cognitive barriers of LARCs. The majority of the studied women $(98.2 \%)$ stated that they did not hear or see any advertisement about LARCs in last 6 months. Regarding demographic and reproductive barriers of LARCs, the majority (92.9\%) of them take their decision about their family planning method on their own without any force from any one.

Table (3): Shows socio cultural barriers of LARCs, $56.4 \%$ of studied women think that loop can move in the body and can penetrate the heart, and about $43.1 \%$ think that injection can cause infertility.
Nearly two thirds (64.9\%) of studied women found that it is reluctance to discuss sexual behaviors and problems with male physicians, and about $50.7 \%$ of them think that it is necessary to have a male boy.

Table (4): Shows administrative barriers of LARCs, $15.6 \%$ of studied women complained of long waiting, and $34.7 \%$ of them were asked to come again when they having period. Concerning method failure and medical barriers of LARCs, $19.1 \%$ of studied women have had failed in using LARCs and about $43.6 \%$ of studied women had side effects. Regarding medical barriers, $15.6 \%$ of studied women stated that LARCs requiring women to return more often for check-ups, and the majority of them $(98.7 \%)$ stated that they not requiring the approval of the partner as a condition for administering contraceptives.

Table (5): Shows the strongest barriers among the current users of LARCs were requiring woman to return for check-ups, then sociocultural barriers, then cognitive barriers, followed by method failure barriers $(88.6 \%, 39.4 \%, 29.8 \%, 12.5 \%)$ respectively. This in contrast with the non-users women, where the strongest barriers were demographic \& reproductive, administrative and requiring spouse consent $(100 \%, 100 \%, 100 \%)$ respectively. There were statistically significant differences among the users and non-users regarding the cognitive and requiring mothers to return for check-ups barriers $(\mathrm{p}=.0001)$, provided that high cognitive level reflect 
low cognitive barriers and low cognitive level reflect high cognitive barriers. But, high level in socio cultural, method failure, demographic \& reproductive, administrative and medical barriers reflect high barriers and low level reflect low barriers in socio cultural, method failure, demographic \& reproductive, administrative and medical barriers.

\section{Discussion}

It is essential for women everywhere to have access to quality contraceptive services to reduce rapid population growth and high birth rates. Even in rural areas of poor countries, women should have the choice of multiple contraceptive methods including not only pills, injectables and barrier methods, but also long-acting methods such as IUCD, implants and sterilization (Ontiri et al., 2019).

The current study showed that more than half of respondents were in the age group 29-40 years with mean age of 30 years ( $\mathrm{SD} \pm 7$ years). This finding agrees with Bolarinwa et al., (2019) who studied about knowledge and factors influencing long acting reversible contraceptive use among women of reproductive age in Nigeria who found that the mean age of respondents was 31.3 years. On the other hand Bikorimana, (2015) who conducted his study about barriers to LARCs usage among married women of reproductive age in Rwanda and found that nearly half of women were in the age group 1825 years.

The present study revealed in that three fifth of women had secondary education level. This finding agrees with Bolarinwa et al., (2019) who found in his study that nearly half of women had secondary education. Also, the present study revealed that more than three quarters of women were housewives. This finding agrees with Azmoude et al., (2017) study about factors affecting the use of long-acting and permanent contraceptive methods among married women of reproductive age in east of Iran. They found that nearly three quarters of women were housewife. The present study showed that more than three quarters of women were residing in rural areas. This finding disagrees with Bolarinwa et al., (2019) who found that $41 \%$ of women resided in rural areas. This reflects the rural Egyptian environment.

The present study found that nearly half of mothers were using LARC methods. This finding agrees with Badia et al., (2019) study about effect of cell-phone assisted postpartum counseling on the use of longacting reversible contraceptives in Assiut, Egypt who reported that more than three quarters of women in the study group were used IUD, injection and implants. Furthermore, Wondie et al., (2020) study about rural-urban differentials of long-acting contraceptive method utilization among reproductive-age women in Ethiopia reported that the prevalence of LARCs use was $23.1 \%$ among rural and urban women.

Whereas, Bikorimana, (2015) found that only $10.4 \%$ of mothers were using LACM. This low utilization rate of LACM in Kicukiro district could be due to the negative attitudes that women have on them and the researcher classified all injectables as short acting methods whereas in the current study progesterone only injectables are to be considered as long acting method.

The present study showed that about one quarter of respondents was using IUD. This finding coincided with Farrag et al., (2020) study about Practice of Family Planning among Married Female Attendants to Shawa Family Health Unit, Dakahlia, Egypt who reported that more than one quarter of studied women were using IUD. On the other hand, Eshak et al., (2018) study in Minia, Upper Egypt, reported that injections were the most frequently ever used methods.

Also, the present study revealed that implants had minimal use by respondents. This finding agrees with Kavanaugh, et al., (2015) study about changes in use of long-acting reversible contraceptive methods among U.S. women who reported that $1.3 \%$ of studied women were using implants. This finding disagrees with Badia et al., (2019) study about effect of cell-phone assisted postpartum counseling on the use of long-acting reversible contraceptives in Assiut, Egypt who reported that $10 \%$ of study group were used implants.

The present study showed that the majority of the studied women mentioned they have not heard or seen any LARCs advertising in the last 6 months and have not engaged in a LARCs educational session in the last 6 months. These results disagree with Badia et al., (2019) results who mentioned that half of our population ever heard about LARC.

The present study showed that more than half of the participants had bad convictions about IUD, e.g. loop can penetrate the heart. These results in jibe with Bhandari et al., (2019) study about long acting reversible contraception use and associated factors among married women of reproductive age in Nepal who reported that younger women with fertility intention feel a fear of side effects or have misconceptions such as LARCs causing infertility and IUCD may move towards heart from uterus.

The present study showed that cognitive barriers were the strongest barriers, and the administrative barriers were the least reported ones. These findings agree with Farrag et al., (2020) who found that cognitive barriers were the main barriers and 
administrative barriers were the least mentioned ones. On the other hand, Bikorimana, (2015) found that most women were aware of modern contraceptives except that its use was minimal and negative attitudes toward LARCs were the main barriers that slow down the use of them. This may be attributed to suggestive views on the obstacles which differ related to community cultural and values.

The present research showed that over two thirds of non-users had cognitive limitations compared with less than one third of users. This study was similar to the finding of Desta \& Worku (2017) study about usage of LARCs among women who want no more children in Ethiopia and stated that, the higher the woman hear about family planning on radio, told about FP by health or FP worker and decision maker on use of contraception were found to be determinants for the use of LARCs. This finding contradicted with Yalew et al., (2015) study about demand for long acting contraceptive methods and associated factors among family planning service users in Ethiopia who found that there was no association between women's cognitive level and the use of LARCs. This is explained by the fact said "women who have good knowledge (high cognitive level) about family planning will weigh fairly the risks and benefits of using contraception and giving sound decision". So, Policy changes in Egypt are required to support LARCs uptake.

\section{Conclusions:}

The current study showed that LARCs utilization still lower than short acting contraception methods and the cognitive barrier is the most significant barrier against LARCs utilization.

\section{Recommendations}

- Increase women's awareness about the importance of using family planning especially long acting reversible contraception methods at a national level.

- Mass media should have a role in providing information to women about long acting reversible contraception methods.

- Educational programs for health workers especially physicians and nurses regarding the importance of long acting reversible contraception.

- Provide motivation for women to attend educational program in the form of free courses, free posters, and booklets.

Acknowledgement: We thank all women for their collaboration in the study

\section{Reference}

- Azmoude, E., (2017): Factors affecting the use of long-acting and permanent contraceptive methods among married women of reproductive age in East of Iran. Women's Health, e44426.

- Badia TS, Moustafa MF, Shaaban OM \& Youness EM (2019): Effect of Cell-Phone Assisted Postpartum Counseling on the Use of Long-Acting Reversible Contraceptives: A Randomized Controlled Trial. Assiut Scientific Nursing Journal; 7 (17):52-61.

- Bhandari R, Pokhrel KN, Gabrielle N, \& Amatya A (2019): Long acting reversible contraception use and associated factors among married women of reproductive age in Nepal. PLoS ONE, 14(3), 1-13. https://doi.org/10.1371/journal.pone.0214590.

- Bikorimana, E., (2015): Barriers to the use of long acting contraceptive methods among married women of reproductive age in Kicukiro District, Rwanda. Int J Sci Res Publ, 5(12), 513-21.

- Bolarinwa, O., \& Olagunju, O., (2019): Knowledge and factors influencing long acting reversible contraceptive use among women of reproductive age in Nigeria [version 1; peer review: awaiting peer review]. Gates Open Research; 3(7). doi10.12688.

- Desta, E., \& Worku, A., (2017): Usage of long acting reversible contraceptive methods among women who want no more children, in-depth analysis of the ethiopian demographic and health survey 2005. Science Journal of Public Health; 5(6): 428-439. Doi: 10.11648/j.sjph.20170506.14. Available at: http://www.sciencepublishinggroup.com/journal/p aperinfo? journalid $=251 \&$ doi $=10.11648 / \mathrm{j} . \mathrm{sjph} .201$ 70506.14. Accessed on 2-10-2020.

- Egypt demographic and health survey (EDHS) (2020): Cairo, Egypt. 9th ed. Ministry of Health and Population: 61-86. Available at: http://www.dhsprogram.com. Accessed on 7-32021.

- El Zanaty K \& Way A (2014): Egypt demographic and health survey. Cairo, Egypt. $9^{\text {th }}$ ed. Ministry of Health and Population: 61-86. Available at: http://www. dhsprogram.com. Accessed on 7-4-2020.

- Eshak ES, Sayed SI, Kamel EG \& El-Sheref MA (2018): Non-medical predictors forever and current use of contraceptives among women in Minia, Upper Egypt. Journal of Public Health, 26(6), 663-671.

- Farrag NS, FathyAA \& Wahab FA (2020): Practice of Family Planning among Married Female Attendants to Shawa Family Health Unit, 
Dakahlia, Egypt. Egyptian Family Medicine Journal (EFMJ); 4(1):24-41.

- Gayatri M (2020): The Utilization of LongActing Reversible Contraception and Associated Factors among Women in Indonesia Global Journal of Health Science; 12 (3): https://doi.org/10.5539/gihs.v12n3p110.

- Kavanaugh, M., et al., (2015): Changes in use of long-acting reversible contraceptive methods among U.S. women, 2009-2012. Obstetrics and gynecology; 126(5): 917-927. doi:10.1097/AOG.0000000000001094.

- Kumari SS (2016): Permanent Sterilisation to Long-Acting Reversible Contraception: Is a Paradigm Shift Necessary? J Obstet Gynaecol India; 66(3):14953.https://doi.org/10.1007/s13224-016-0866-2.

- Ontiri, S., Ndirangu, G., Kabue, M., Biesma, R., Stekelenburg, J., \& Ouma, C. (2019): Long-acting reversible contraception uptake and associated factors among women of reproductive age in rural Kenya. International Journal of Environmental Research and Public Health, 16(9),

$1-11$.

https://doi.org/10.3390/ijerph16091543.

- Wondie KY, Badi MB \& Tamiru AT (2020): Rural-Urban Differentials of Long-Acting Contraceptive Method Utilization Among Reproductive-Age Women in Amhara Region, Ethiopia: Further Analysis of the 2016 EDHSThis article was published in the following Dove Press journal: Open Access Journal of Contraception. Open Access Journal of Contraception; 11: 77-89.

- Yalew, S., et al., (2015): Demand for long acting contraceptive methods and associated factors among family planning service users, Northwest Ethiopia: a health facility based cross sectional study. BMC research notes, 8(1), 29.

- Zenebe CB, Adefris M, Kindie M, et al. (2017): Factors associated with utilization of long-acting and permanent contraceptive methods among women who have decided not to have more children in Gondar city. BMC Women's Health; 17(75). Doi: 10.1186/s12905017-0432-9. 